\title{
Serum Paraoxonase/Arylesterase 2
}

National Cancer Institute

\section{Source}

National Cancer Institute. Serum Paraoxonase/Arylesterase 2. NCI Thesaurus. Code C113557.

Serum paraoxonase/arylesterase 2 ( $354 \mathrm{aa}, \sim 39 \mathrm{kDa}$ ) is encoded by the human PON2 gene. This protein may play a role as a cellular antioxidant. 